\title{
Measurement of Transient Permeability of Sp2/0 Myeloma Cells: Flow Cytometric Study
}

\author{
Vitalij Novickij ${ }^{1}$, Irutè Girkontaité2 ${ }^{2}$ Audrius Grainys ${ }^{1}$, Auksè Zinkevičiené2 $\dot{e}^{2}$ Eglè Lastauskiené ${ }^{3}$, \\ Jurgita Švediené ${ }^{4}$, Algimantas Paškevičius ${ }^{4}$, Svetlana Markovskaja ${ }^{5}$, Jurij Novickij ${ }^{1}$ \\ ${ }^{1}$ Institute of High Magnetic Fields, Faculty of Electronics, Vilnius Gediminas Technical University, Naugarduko g. 41, \\ 03227, Vilnius, Lithuania, vitalij.novickij@vgtu.lt \\ ${ }^{2}$ State Research Institute Centre for Innovative Medicine, Department of Immunology, Santariškiu g. 5, 08406, Vilnius, \\ Lithuania \\ ${ }^{3}$ Department of Microbiology and Biotechnology, Vilnius University, Sauletekio al. 9, 10221, Vilnius, Lithuania \\ ${ }^{4}$ Department of Biodeterioration Research, Nature Research Centre, Akademijos str. 2, 08412, Vilnius, Lithuania \\ ${ }^{5}$ Laboratory of Mycology, Nature Research Centre, Akademijos str. 2, 08412, Vilnius, Lithuania
}

\begin{abstract}
Electroporation is an electric field induced phenomenon occurring when the permeability of the cell membrane is increased due to the excess of critical transmembrane potential. Fluorescent dye assays are frequently used for evaluation of the permeabilization rate, however, the protocols vary, which negatively affects the repeatability of the results. In this work we have designed experiments to investigate the protocols and threshold concentrations of the Propidium Iodide (PI) and YO-PRO-1 (YP) fluorescent dyes for evaluation of mammalian cell permeabilization induced by electroporation. The Sp2/0 mouse myeloma cells were used and the bursts of $100 \mu$ s 8 electrical pulses of $0.8-2 \mathrm{kV} / \mathrm{cm}$ were applied. It has been shown that the dye concentration has an influence on the detectable permeabilization, and the concentrations below $30 \mu \mathrm{M}$ for PI and $1 \mu \mathrm{M}$ for YP should be avoided for measurement of electropermeabilization efficacy due to unreliable fluorescence signals. Further, based on the experimental data, the permeabilization curve for the Sp2/0 myeloma cells in the $0.8-2 \mathrm{kV} / \mathrm{cm}$ range has been presented.
\end{abstract}

Keywords: Electroporation, BD FACS Calibur, Amnis FlowSight, Sp2/0 myeloma cells.

\section{INTRODUCTION}

Electroporation is a technique which allows inducing transient or permanent increased permeability to the cell membrane using pulsed electric fields (PEF) [1]-[3]. Capability to control the permeability of the membrane to various macromolecules allowed to develop a vast array of biotechnological and biomedical methods, such as drug delivery, electrochemotherapy, gene delivery, and many others [3]-[6].

The permeabilization effect is triggered when the steady state of the critical transmembrane potential is achieved (typically in the range of $1 \mathrm{~V}$ ), however, the electric field amplitude to induce such a potential is cell type dependent and varies significantly (by several factors), depending on the biological object [7], [8]. Also the exact PEF effect depends on the waveform, duration, number of pulses and other parameters, thus the research of the equivalent pulse parameters including effective protocols is constantly performed [9]-[11]. The parametric analysis is required each time a new cell type/strain is used due to the differences in the structure of the membrane, which results in a unique permeabilization curve for each cell type [12]-[13]. Typically, fluorescent dye assays are used for evaluation of the permeability by means of fluorescent microscopy and flow cytometry, while the Propidium Iodide (PI) and YOPRO-1 (YP) dyes are the most common [14]-[17]. The evaluation of the transient permeability by PEF is complicated due to the rapid dynamics of the process [18][20]. The induced porosity of the cell membrane can be altered within seconds, while the dye diffusion and the polarization effects due to PEF depend both on the dye concentration and PEF parameters (additional ion interaction) and thus influence the efficacy of the dye uptake.

In the current state, the protocols for flow cytometry for evaluation of the transient permeability (induced by PEF) are not standardized, which negatively affects the repeatability of experiments. The factors such as limitations of instrumental infrastructure, toxicity of the dyes, and dyebinding time are also not taken into account.

Therefore, in this work we have designed experiments to investigate the permeabilization curve of Sp2/0 myeloma 
cells by different staining protocols. We have covered the concentration ranges that are typically used in the PEF studies [14]-[17]. Two different flow cytometric systems have been employed - FACSCalibur (Becton Dickinson Biosciences, San Jose, California, USA) and FlowSight (Amnis, Seattle, USA). Both systems are popular worldwide for the evaluation of the cell permeability, including the PEF induced effects [21]-[24].

The aim was to determine the $\mathrm{Sp} 2 / 0$ permeabilization curve in the $0.8-2 \mathrm{kV} / \mathrm{cm}$ range, investigate the differences between the PI and YP assays, determine minimum concentration thresholds for reliable fluorescence signals, and propose a protocol, which will allow accurate determination of electro-permeabilization in mammalian cells without special requirements for high-end fluorescence systems to produce a stable result.

\section{SUBJECT \& METHODS}

\section{A. Electroporation setup}

For the electroporation experiments, the $3 \mathrm{kV}$, $60 \mathrm{~A}$ square wave pulse generator, that was developed in the Institute of High Magnetic Fields (VGTU, Vilnius, Lithuania), has been used [25]. The pulses were generated in a commercially available electroporation cuvette with $1 \mathrm{~mm}$ gap between the electrodes (BTX, Cuvette Nr. 610, San Diego, USA). Bursts of $0.8-2 \mathrm{kVcm}^{-1}$ electric field pulses with duration of $100 \mu$ s were applied (total of 8 pulses). A repetitive frequency of the pulses was set to $1 \mathrm{kHz}$.

The waveform of the applied pulses is shown in Fig.1.

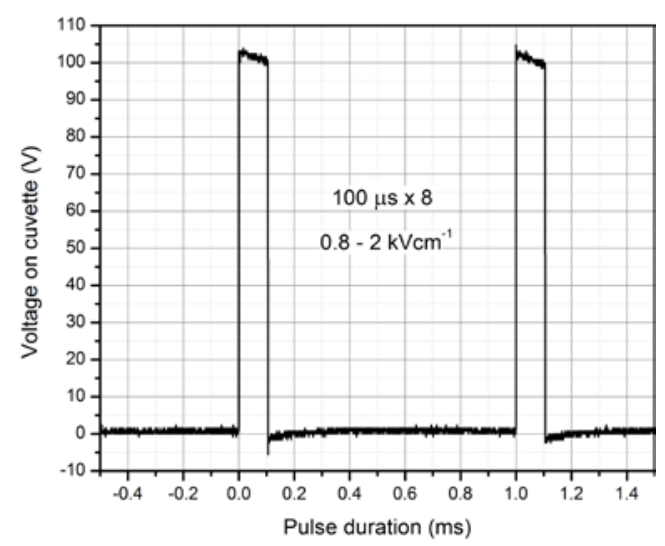

Fig.1. The waveform of the applied electrical pulses.

The voltage supplied to the cuvette has been varied in the $80-200 \mathrm{~V}$ range, which corresponds to the electric field of $0.8-2 \mathrm{kVcm}^{-1}$.

\section{B. Biological cells and flow cytometry}

Sp2/0 mouse myeloma cells were cultured in RPMI 1640 medium supplemented with $10 \%$ fetal calf serum, $2 \mathrm{mM}$ glutamine, $100 \mathrm{U} / \mathrm{ml}$ penicillin, and $100 \mu \mathrm{g} / \mathrm{ml}$ streptomycin (Gibco, Thermo Fisher Scientific, USA) at $37^{\circ} \mathrm{C}, 5 \% \mathrm{CO}_{2}$. For electroporation, the cells were re-suspended at concentration $5 \times 10^{6}$ cells/ml in RPMI medium without supplementals. $70 \mu \mathrm{l}$ of cell suspension was mixed with
Propidium Iodide (PI) or YO-PRO-1 (YP) (Sigma-Aldrich, Germany) fluorescence dye and transferred to the electroporation cuvette. Four different dye concentrations, both for the PI and YP, have been used in the study. For the PI we have used $7.5-45 \mu \mathrm{M}$ and for YP the $0.2-10 \mu \mathrm{M}$ concentrations were selected, which is in agreement with the typical values of fluorescent dye concentrations used for electroporation [14]-[17]. After the pulsing procedure the cells were stored at room temperature (3 min) for staining. Later, the cells were transferred to flow cytometry tubes with $200 \mu \mathrm{l}$ PBS buffer and the fluorescence was analyzed using BD FACSCalibur (Becton Dickinson Biosciences, San Jose, California, USA) and Cell Quest software.

Alternatively, the cells (after pulsing) were transferred to $1.5 \mathrm{~mL}$ tubes (Eppendorf, Hamburg, Germany) for analysis by FlowSight (Amnis, Seattle, USA) flow cytometer and IDEAS software (Amnis, Seattle, USA) was used for data processing.

Example of the fluorescence spectra and the gate definition, which is typical for electroporation studies for measurement of electroporation effect using flow cytometry [26], is shown in Fig.2.

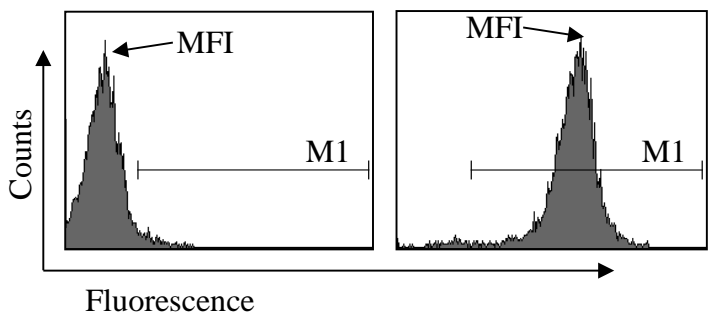

Fig.2. Example of the fluorescence spectra and the gate definition (M1); Left: control without treatment; Right: Sample after PEF treatment, where MFI - mean fluorescence intensity

The gate M1 has been positioned in the control sample to be in agreement with the vitality data of the cells before the treatment, which was acquired using the vital stain Trypan Blue (Gibco, Thermo Fisher Scientific, USA) and evaluated by light microscopy (Olympus CKX31, Japan). The number of cells with compromised membrane before PEF treatment did not exceed $10 \%$ in all experimental instances. After the treatment, the shift of spectra has been observed and the cells in the gate M1 have been defined as fluorescent positive (permeabilized), while the cells outside the gate as fluorescent negative (non-permeabilized).

To determine the cell viability after the pulsing, the cells were electroporated without any staining. The majority of reversible electroporation induced pores reseal very fast (ms range) [18]-[20], while complete pore resealing may take up to several minutes [27], therefore the cells were stained after a $30 \mathrm{~min}$ delay with $0.1 \mu \mathrm{M}$ of YP and $1 \mu \mathrm{g} / \mathrm{ml}$ PI, followed by a $20 \mathrm{~min}$ staining protocol [28]. The resultant fluorescence was analyzed using FlowSight (Amnis, Seattle, USA) flow cytometer. The cells were identified as viable, if both the YP and PI negative fluorescence was observed. Further, the number of YP/PI negative cells was expressed as a percentage of the total number of cells. 


\section{Statistical analysis}

At least three independent experimental sessions have been performed for each unique set of parameters. Statistical analysis has been performed on all of the acquired data (OriginPro 8.5, OriginLab, Northhampton, MA, USA). The paired t-test was used for the estimation of the statistical significance. The results were considered statistically significant at $\mathrm{P}<0.05$.

\section{Results}

The cells have been subjected to pulsed electric field of $0.8-2 \mathrm{kVcm}^{-1}$ with different fluorescent dye concentrations present in the medium. The resultant permeabilization curves of Sp2/0 cells using the YP and PI assays are shown in Fig.3. (measured using BD FACSCalibur). The viability curve (dashed line, measured using Amnis FlowSight) is presented in superposition to the permeability results.

As can be seen in Fig.3. (Top), the $1-10 \mu \mathrm{M}$ concentrations of YP showed low variation in values. High permeability ( $>90 \%$ ) was observed when the electric field exceeded $1.2 \mathrm{kVcm}^{-1}$. The viability curve is in agreement with the permeabilization data and indicates that a trade-off between the number of permeabilized and viable cells should be made, since the number of irreversibly permeabilized cells increases with the intensity of the treatment. The $0.2 \mu \mathrm{M}$ concentration of $\mathrm{YP}$ was inadequate for the selected protocol.

The PI assay showed a higher discrepancy in the results (Fig.3. bottom). Similar to the YP $0.2 \mu \mathrm{M}$ case, the low concentrations of the PI (7.5-15 $\mu \mathrm{M})$ distorted the curves the viability and the permeabilization data were controversial, i.e., the number of fluorescent cells was lower than the number of non-viable cells. However, further increase of the concentration to $(30-45 \mu \mathrm{M})$ was sufficient enough for the YP and PI results to be in compliance without a statistically significant difference.

We have further evaluated the mean fluorescence intensity (MFI) of the samples after the treatment (measured using BD FACSCalibur). The results are summarized in Fig.4. The highest mean fluorescence intensity has been acquired using the PI dye with high concentration $(45 \mu \mathrm{M})$ followed by a $10 \mu \mathrm{M}$ YP assay.

The low concentration of the dyes resulted in low mean fluorescence. We were not able to observe a statistically significant difference between the PI 7.5-15 $\mu \mathrm{M}$ and YP $0.2-1 \mu \mathrm{M}$ protocols.

Further, the Amnis FlowSight system has been employed in the study and the darkfield (side scatter), brightfield, and fluorescence images of each cell have been acquired (total of 10000 cells for each unique set of parameters).

The typical images of PI fluorescence (21 cells randomly selected from each experimental instance), which accurately represent the generality of the observation in the control samples without any treatment and samples after high PEF permeabilization, are presented in Fig.5. The fluorescence of the non-treated cells (Fig.5.a) did not depend on the dye concentration due to the non-compromised membrane integrity. The $1.4 \mathrm{kVcm}^{-1}$ protocol has been used to induce high permeabilization (See Fig.3.).
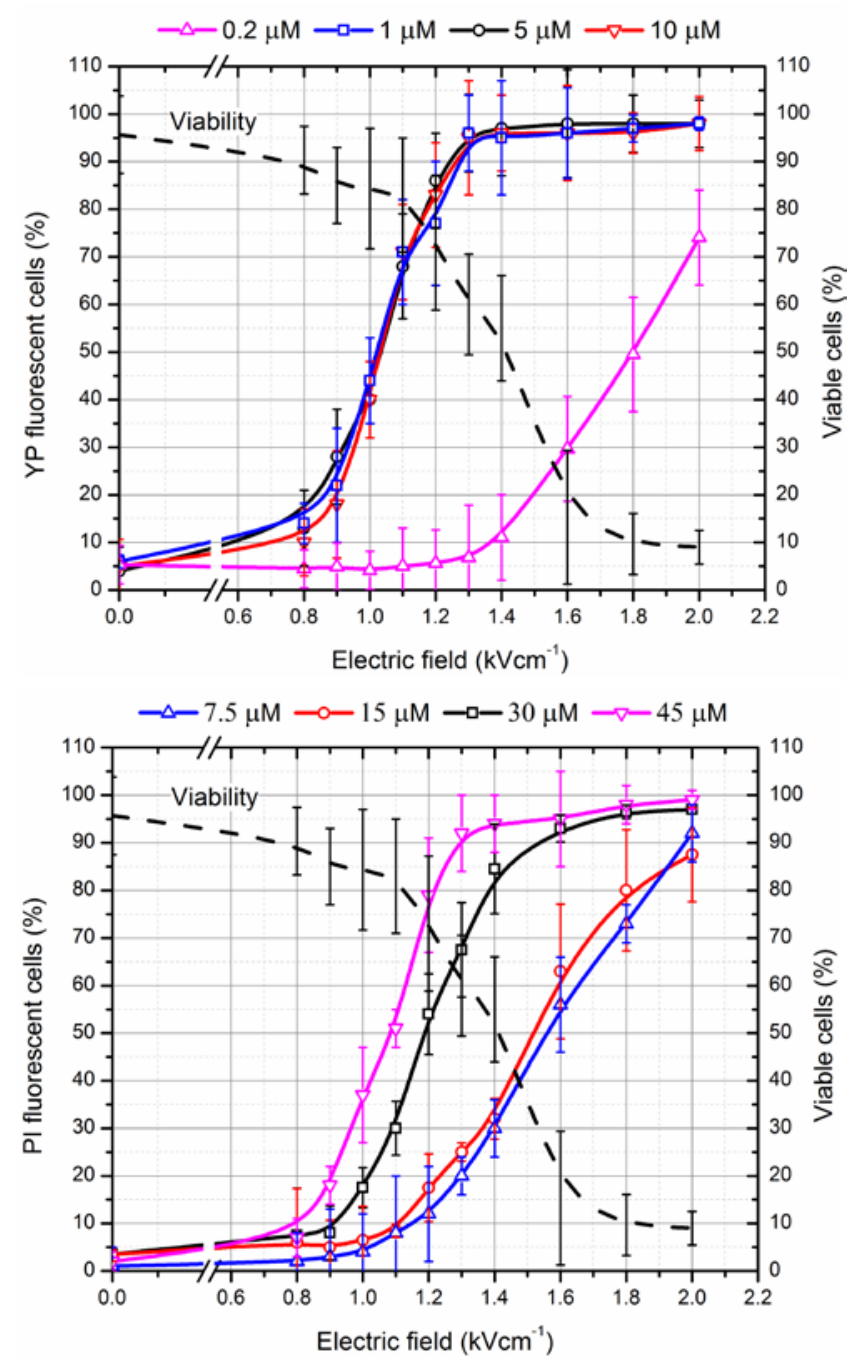

Fig.3. Sp2/0 cells permeabilization and viability curves using fluorescent dyes of different concentration, Top: YP $(0.2-10 \mu \mathrm{M})$; Bottom: PI (7.5-45 $\mu \mathrm{M})$.

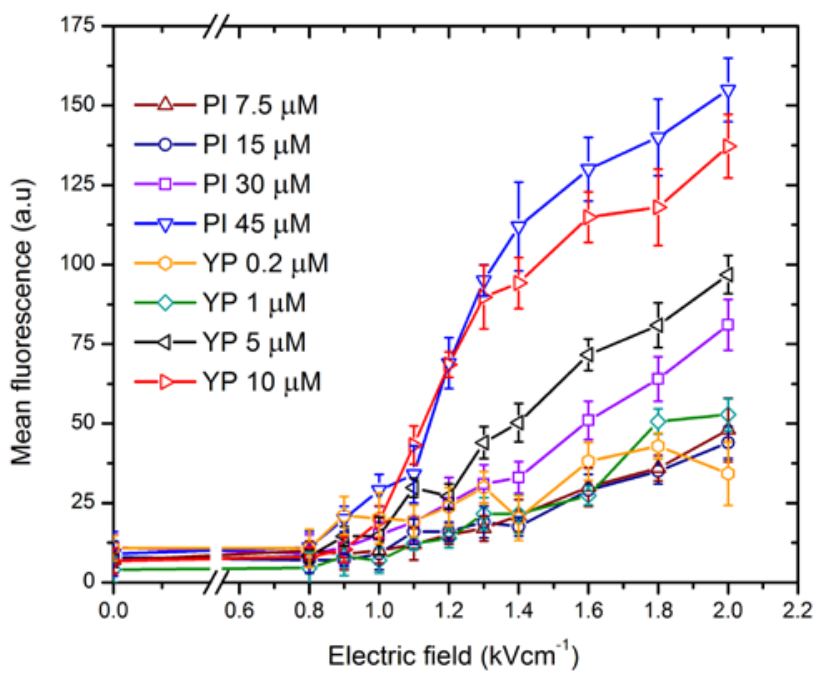

Fig.4. Mean fluorescence intensity dependence on PEF parameters. 

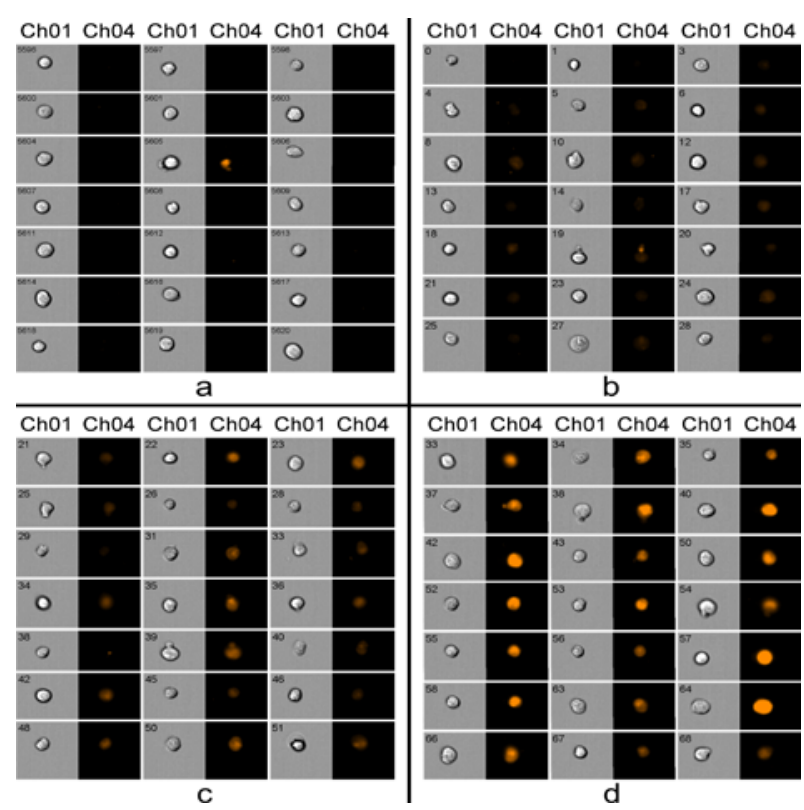

Fig.5. PI fluorescence of Sp2/0 cells before and after $1,4 \mathrm{kVcm}^{-1}$ $100 \mu$ s x 8 PEF, where a) non-treated control; b) after PEF, $7.5 \mu \mathrm{M}$ PI; c) after PEF, $30 \mu \mathrm{M}$ PI; d) after PEF, $45 \mu \mathrm{M}$ PI; Ch01 brightfield image; Ch04 - fluorescence image at wavelength of $488 \mathrm{~nm}$.

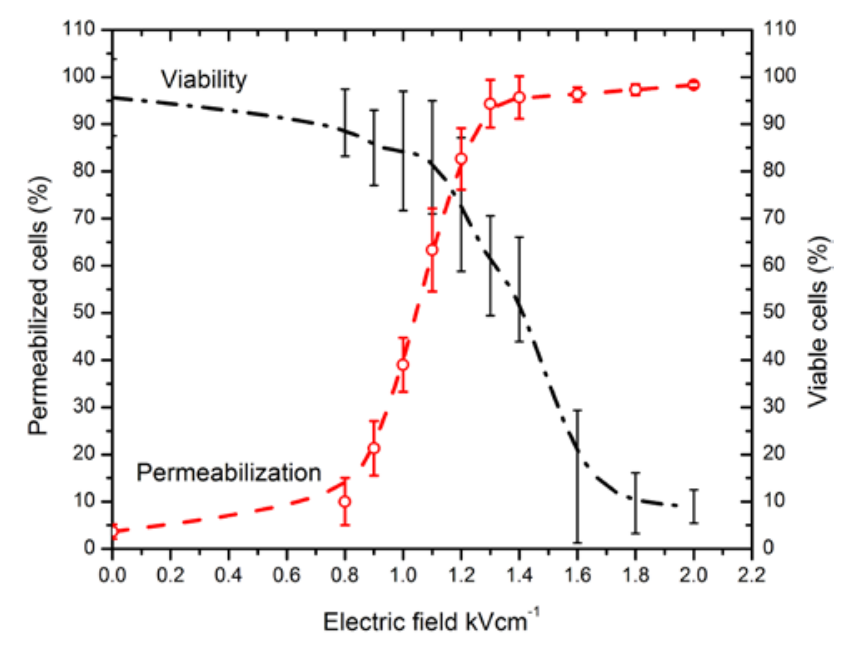

Fig.6. Permeabilization and viability curves for Sp2/0 myeloma cells (average of $45 \mu \mathrm{M}$ PI and 1-10 $\mu \mathrm{M}$ YP protocols).

However, the number of fluorescent cells was significantly lower (Fig.5.b) in the $7.5 \mu \mathrm{M}$ PI protocol case and an incremental tendency was observed with increase of the dye concentration (Fig.5.c), d), which is in agreement with the flow-cytometry data that was acquired by the BD FACSCalibur system (See Fig.3., bottom).

Finally, the permeabilization curve for the Sp2/0 myeloma cell line was determined as average of $45 \mu \mathrm{M}$ PI and 1-10 $\mu \mathrm{M}$ YP instances. The superposition of the permeability and viability curves is shown in Fig.6.

As can be seen in Fig.6., the PEF induced permeabilization is triggered in the $0.8-0.9 \mathrm{kVcm}^{-1}$ range (10-20\%), followed by a rapid increase (up to $95 \%$ ) when the $1.4 \mathrm{kVcm}^{-1} \mathrm{PEF}$ is applied.
Taking into account the number of irreversibly permeabilized cells, the $1.1-1.2 \mathrm{kVcm}^{-1} 100 \mu \mathrm{s} \times 8$ protocol is optimal for triggering high transient permeability with minimum loss in viability for the Sp2/0 myeloma cell line.

\section{CONCLUSION}

It has been concluded that the concentration of the fluorescent dye influences the transient permeability data after electroporation. Low dye concentrations, both for PI (7.5-15 $\mu \mathrm{M})$ and YP $(0.2 \mu \mathrm{M})$, result in distortion of the permeabilization curve and further controversy with viability data. The effect is influenced by the resultant low mean fluorescence after excitation and, thus, low sensitivity to changes in transient permeability of the cells.

It was determined that application of dye concentrations above $30 \mu \mathrm{M}$ for PI and $1 \mu \mathrm{M}$ for YP allows accurate determination of electro-permeabilization in Sp2/0 myeloma cells without special requirements for highly sensitive fluorescence systems to produce a stable result. While it is still possible to detect fluorescence of dyes with lower concentrations by high-end flow cytometric infrastructure, the fluorescence microscopy and or low sensitivity flow cytometric instrumentation is not applicable, which severely impairs the repeatability of the scientific findings.

It has been determined that the $1.1-1.2 \mathrm{kVcm}^{-1} 100 \mu \mathrm{s} \times 8$ protocol allows to achieve high electric field induced cell permeabilization with minimum loss in viability for the Sp2/0 myeloma cell line.

\section{ACKNOWLEDGMENT}

This work was supported by the Research Council of Lithuania towards the Future Technologies Program project Nr. LAT-02/2016.

\section{REFERENCES}

[1] Gehl, J. (2003). Electroporation: Theory and methods, perspectives for drug delivery, gene therapy and research. Acta Physiologica Scandinavica, 177 (4), 437-447.

[2] Kotnik, T., Kramar, P., Pucihar, G., Miklavcic, D., Tarek, M. (2012). Cell membrane electroporation Part 1: The phenomenon. IEEE Electrical Insulation Magazine, 28 (5), 14-23.

[3] Yarmush, M.L., Golberg, A., Serša, G., Kotnik, T., Miklavčič, D. (2014). Electroporation-based technologies for medicine: Principles, applications, and challenges. Annual Review of Biomedical Engineering, 16 (1), 295-320.

[4] Subhra, T., Wang, P., Gang, F. (2013). Electroporation based drug delivery and its applications. In Advances in Micro/Nano Electromechanical Systems and Fabrication Technologies. InTech, 61-98.

[5] Haberl, S., Miklavcic, D., Sersa, G., Frey, W., Rubinsky, B. (2013). Cell membrane electroporation Part 2: The applications. IEEE Electrical Insulation Magazine, 29 (1), 29-37.

[6] Jiang, C., Davalos, R.V., Bischof, J.C. (2015). A review of basic to clinical studies of irreversible electroporation therapy. IEEE Transactions on Biomedical Engineering, 62 (1), 4-20. 
[7] Teissié, J., Golzio, M. (2014). Electropermeabilization of the cell membrane. In Encyclopedia of Applied Electrochemistry. Springer, 773-782.

[8] Zou, Y., Wang, C., Peng, R., Wang, L., Hu, X. (2015). Theoretical analyses of cellular transmembrane voltage in suspensions induced by high-frequency fields. Bioelectrochemistry, 102, 64-72.

[9] Spugnini, E.P., Melillo, A., Quagliuolo, L., Boccellino, M., Vincenzi, B., Pasquali, P. et al. (2014). Definition of novel electrochemotherapy parameters and validation of their in vitro and in vivo effectiveness. Journal of Cellular Physiology, 229 (9), 1177-1181.

[10] Blumrosen, G., Abazari, A., Golberg, A., Tonner, M., Yarmush, M.L. (2014). Efficient procedure and methods to determine critical electroporation parameters. In 2014 IEEE 27th International Symposium on Computer-Based Medical Systems. IEEE, 314-318.

[11] Pucihar, G., Krmelj, J., Reberšek, M., Napotnik, T.B., Miklavčič, D., Reberšek, M. et al. (2011). Equivalent pulse parameters for electroporation. IEEE Transactions on Biomedical Engineering, 58 (11), 3279-3288.

[12] Pucihar, G., Kotnik, T., Kandušer, M., Miklavčič, D. (2001). The influence of medium conductivity on electropermeabilization and survival of cells in vitro. Bioelectrochemistry, 54 (2), 107-15.

[13] Rols, M.P., Teissié, J. (1990). Electropermeabilization of mammalian cells. Quantitative analysis of the phenomenon. Biophysical Journal, 58 (5), 1089-1098.

[14] Vernier, P.T., Sun, Y., Gundersen, M.A., Vernier, P., Sun, Y., Marcu, L. et al. (2006). Nanoelectropulsedriven membrane perturbation and small molecule permeabilization. BMC Cell Biology, 7 (1), 37.

[15] Napotnik, T.B., Wu, Y.-H., Gundersen, M.A., Miklavčič, D., Vernier, P.T. (2012). Nanosecond electric pulses cause mitochondrial membrane permeabilization in Jurkat cells. Bioelectromagnetics, 33 (3), 257-264.

[16] Djuzenova, C.S., Zimmermann, U., Frank, H., Sukhorukov, V.L., Richter, E., Fuhr, G. (1996). Effect of medium conductivity and composition on the uptake of propidium iodide into electropermeabilized myeloma cells. Biochimica et Biophysica Acta Biomembranes, 1284 (2), 143-152.

[17] Sadik, M.M., Li, J., Shan, J.W., Shreiber, D.I., Lin, H. (2013). Quantification of propidium iodide delivery using millisecond electric pulses: Experiments. Biochimica et Biophysica Acta - Biomembranes, 1828 (4), 1322-1328.

[18] Demiryurek, Y., Nickaeen, M., Zheng, M., Yu, M., Zahn, J.D., Shreiber, D.I. et al. (2015). Transport, resealing, and re-poration dynamics of two-pulse electroporation-mediated molecular delivery. Biochimica et Biophysica Acta - Biomembranes, 1848 (8), 1706-1714.
[19] Gowrishankar, T.R., Pliquett, U., Lee, R.C. (1999). Dynamics of membrane sealing in transient electropermeabilization of skeletal muscle membranes. Annals of the New York Academy of Sciences, 888 195-210.

[20] Saulis, G. (2010). Kinetics of pore formation and disappearance in the cell during electroporation. In Advanced Electroporation Techniques in Biology and Medicine. CRC Press, 213-237.

[21] Lamberti, P., Romeo, S., Sannino, A., Zeni, L., Zeni, O. (2015). The role of pulse repetition rate in nsPEFinduced electroporation: A biological and numerical investigation. IEEE Transactions on Biomedical Engineering, 62 (9), 2234-2243.

[22] Kulbacka, J., Pucek, A., Wilk, K.A., DubińskaMagiera, M., Rossowska, J., Kulbacki, M. et al. (2016). The effect of millisecond pulsed electric fields (msPEF) on intracellular drug transport with negatively charged large nanocarriers made of solid lipid nanoparticles (SLN): In vitro study. The Journal of Membrane Biology, 249 (5), 645-661.

[23] Ford, W.E., Ren, W., Blackmore, P.F., Schoenbach, K.H., Beebe, S.J. (2010). Nanosecond pulsed electric fields stimulate apoptosis without release of proapoptotic factors from mitochondria in B16f10 melanoma. Archives of Biochemistry and Biophysics, 497 (1-2), 82-89.

[24] Wezgowiec, J., Derylo, M.B., Teissie, J., Orio, J., Rols, M.-P., Kulbacka, J. et al. (2013). Electric fieldassisted delivery of photofrin to human breast carcinoma cells. The Journal of Membrane Biology, 246 (10), 725-735.

[25] Novickij, V., Grainys, A., Butkus, P., Tolvaišienè, S., Švedienè, J., Paškevičius, A., Novickij, J. (2016). High-frequency submicrosecond electroporator. Biotechnology and Biotechnological Equipment, 30 (3), 607-613.

[26] Michie, J., Janssens, D., Cilliers, J., Smit, B.J., Böhm, L. (2000). Assessment of electroporation by flow cytometry. Cytometry, 41, 96-101.

[27] Bier, M., Hammer, S.M., Canaday, D.J., Lee, R.C. (1999). Kinetics of sealing for transient electropores in isolated mammalian skeletal muscle cells. Bioelectromagnetics, 20 (3), 194-201.

[28] Lazniewska, J., Janaszewska, A., Miłowska, K., Caminade, A.M., Mignani, S., Katir, N., El Kadib, A., Bryszewska, M., Majoral, J.P., Gabryelak, T., Klajnert-Maculewicz, B. (2013). Promising lowtoxicity of viologen-phosphorus dendrimers against embryonic mouse hippocampal cells. Molecules, 18 (10), 12222-12240. 